\title{
Fuzzy logic algorithm for runoff-induced sediment transport from bare soil surfaces
}

\author{
Gokmen Tayfur $^{\mathrm{a}, *}$, Serhan Ozdemir ${ }^{\mathrm{b}}$, Vijay P. Singh ${ }^{\mathrm{c}}$ \\ a Department of Civil Engineering, Izmir Institute of Technology, Izmir, Urla, Turkey \\ ${ }^{\mathrm{b}}$ Department of Mechanical Engineering, Izmir Institute of Technology, Izmir, Urla, Turkey \\ ${ }^{\mathrm{c}}$ Department of Civil and Environmental Engineering, Louisiana State University, Baton Rouge, LA 70803-6405, USA
}

Received 3 November 2002; received in revised form 27 July 2003; accepted 3 August 2003

\begin{abstract}
Utilizing the rainfall intensity, and slope data, a fuzzy logic algorithm was developed to estimate sediment loads from bare soil surfaces. Considering slope and rainfall as input variables, the variables were fuzzified into fuzzy subsets. The fuzzy subsets of the variables were considered to have triangular membership functions. The relations among rainfall intensity, slope, and sediment transport were represented by a set of fuzzy rules. The fuzzy rules relating input variables to the output variable of sediment discharge were laid out in the IF-THEN format. The commonly used weighted average method was employed for the defuzzification procedure.

The sediment load predicted by the fuzzy model was in satisfactory agreement with the measured sediment load data. Predicting the mean sediment loads from experimental runs, the performance of the fuzzy model was compared with that of the artificial neural networks (ANNs) and the physics-based models. The results of showed revealed that the fuzzy model performed better under very high rainfall intensities over different slopes and over very steep slopes under different rainfall intensities. This is closely related to the selection of the shape and frequency of the fuzzy membership functions in the fuzzy model.
\end{abstract}

(C) 2003 Elsevier Ltd. All rights reserved.

Keywords: Fuzzy logic; Sediment transport; Artificial neural networks; Physics-based model

\section{Introduction}

Runoff-induced sediment transport models can be classified as black-box models [10], regression-based models [13,17], stochastic models [14] and physics-based models $[8,22,29-33]$.

Although few physically-based models have analytical solutions $[7,21,25]$, most of them involve numerical solutions of systems of partial differential equations. For realistic simulations, these models require data on model parameters at each node of the computational mesh. However, such data at a very fine scale are rarely available. Even if they were available, numerical problems, such as related to convergence and numerical instability, might occur [35]. Hence, such drawbacks have provided impetus to look for new alternative techniques. Intelligence methods, such as the artificial neural networks (ANNs) and the fuzzy logic algorithm, have been

\footnotetext{
${ }^{*}$ Corresponding author.

E-mail address: tayfur@likya.iyte.edu.tr (G. Tayfur).
}

such new alternatives developed in this last decade in the modeling of hydrological processes.

The ANNs have been successfully employed in modeling a wide range of hydrologic processes, including rainfall-runoff processes $[9,37,38]$, streamflows $[19,36]$, water quality $[3,16]$, groundwater flow and quality [24,42], and erosion and sediment transport [34]. The main advantage of using neural networks is that hydrologic processes can be synthesized without making use of the detailed and explicit knowledge of the underlying physics. However, limited or noisy training data may result in an inconsistent and meaningless output.

The fuzzy logic algorithm, which has the ability to describe the knowledge in a descriptive human-like manner in the form of simple rules using linguistic variables, has also been employed in the study of the hydrological processes. In erosion studies, it has been employed to predict soil erosion, to form erosion classes, and to improve the predictions of the conventional models. Mitra et al. [18] developed a fuzzy logic model 
to predict soil erosion in a relatively large watershed using a limited number of input variables. They constructed two different fuzzy logic rule bases: (1) Two inputs of slope angle and land-use ratio; and (2) Three inputs of slope length, soil erodibility, and vegetative cover. They pointed out that the fuzzy logic prediction models were more successful than the USLE in locating and differentiating areas of soil erosion with minimum input data. Ahamed et al. [1] used a fuzzy class membership approach to assign partial grades to the erosion classes. By doing so, they captured the loss of information as a result of assigning a given area element, within which the soil and other physical parameters might vary spatially, to a single erosion class. Tran et al. [39] developed a fuzzy-rule based model to improve the performance of the revised universal soil loss equation (RUSLE). Their approach consisted of two approaches: (1) Multobjective fuzzy regression (MOFR); and (2) Fuzzy rule-based modeling (FRBM). They first applied MOFR to small subsets of the RUSLE factor values to derive the relationship between the soil loss and the rainfall erosivity factor within each subset of data. Then they linked these simple fuzzy rules together in a FRBM framework to form a fuzzy rule set. Thereafter, they successfully applied the fuzzy rule set to compute the soil loss prediction corresponding to each combination of the RUSLE factors. They pointed out that the fuzzy logic-based modeling approach makes the structure of RUSLE more flexible in describing the relationship between soil erosion and other factors and in dealing with data and model uncertainties.

The fuzzy logic algorithm has also been successfully employed in the studies of watershed management $[4,23]$; hydro-ecological modeling over watersheds of mesoscale size [44]; rainfall-runoff processes [20,43]; flood forecasting [40]; water quality problems [15]; and solute transport in saturated/unsaturated zones $[5,6]$. The objective of this study is to develop a fuzzy logic algorithm to predict runoff-driven sediment loads from bare soil surfaces, and to compare the performance of the fuzzy model with that of ANNs and physics-based models.

\section{Mathematical development}

\subsection{Fuzzy logic}

A general fuzzy system, as shown in Fig. 1, has the components of fuzzification, fuzzy rule base, fuzzy output engine, and defuzzification. Fuzzification converts each piece of input data to degrees of membership by a look-up in one or more several membership functions. The key idea in fuzzy logic is the allowance of partial belongings of any object to different subsets of a universal set, instead of completely belonging to a single set. Partial belonging to a set can be described numerically by a membership function, which assumes values between 0 and 1 inclusive. Intuition, inference, rank ordering, angular fuzzy sets, neural networks, genetic algorithms, and inductive reasoning can be among many ways to assign membership values or functions to fuzzy variables. Especially, the intuitive approach is used rather commonly because it is simply derived from the innate intelligence and understanding of human beings. Fuzzy membership functions may take on many forms, but in practical applications simple linear functions such as triangular ones are preferable.

In this study, taking the experimental data into consideration, rainfall intensity, slope, and sediment discharge were fuzzified [27] into fuzzy subsets in order to cover the whole range of changes. The maximum rainfall intensity is considered as $120 \mathrm{~mm} / \mathrm{h}$ and its subdivision into four subsets as low (L), medium (M), high $(\mathrm{H})$, and very high $(\mathrm{VH})$ is considered to have triangular membership functions as represented in Fig. 2a. Similarly, slope is considered to have a maximum value of $40 \%$ and its subdivision into six subsets as mild (M1), VMl, steep (S), LS, HS, and VS is considered to have triangular membership functions as represented in

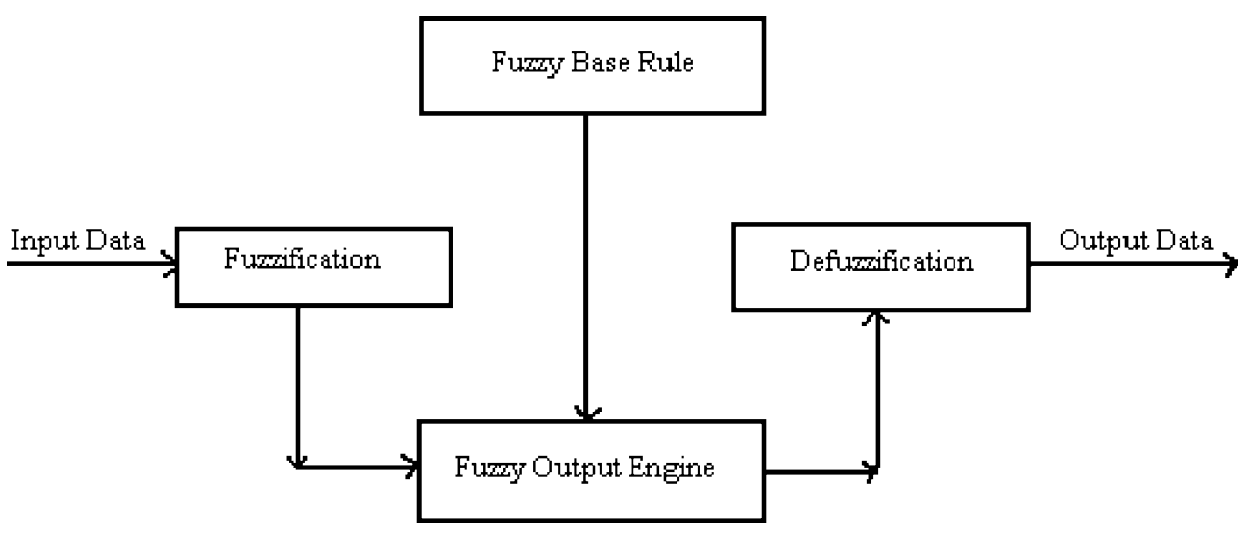

Fig. 1. Schematic representation of a fuzzy system. 

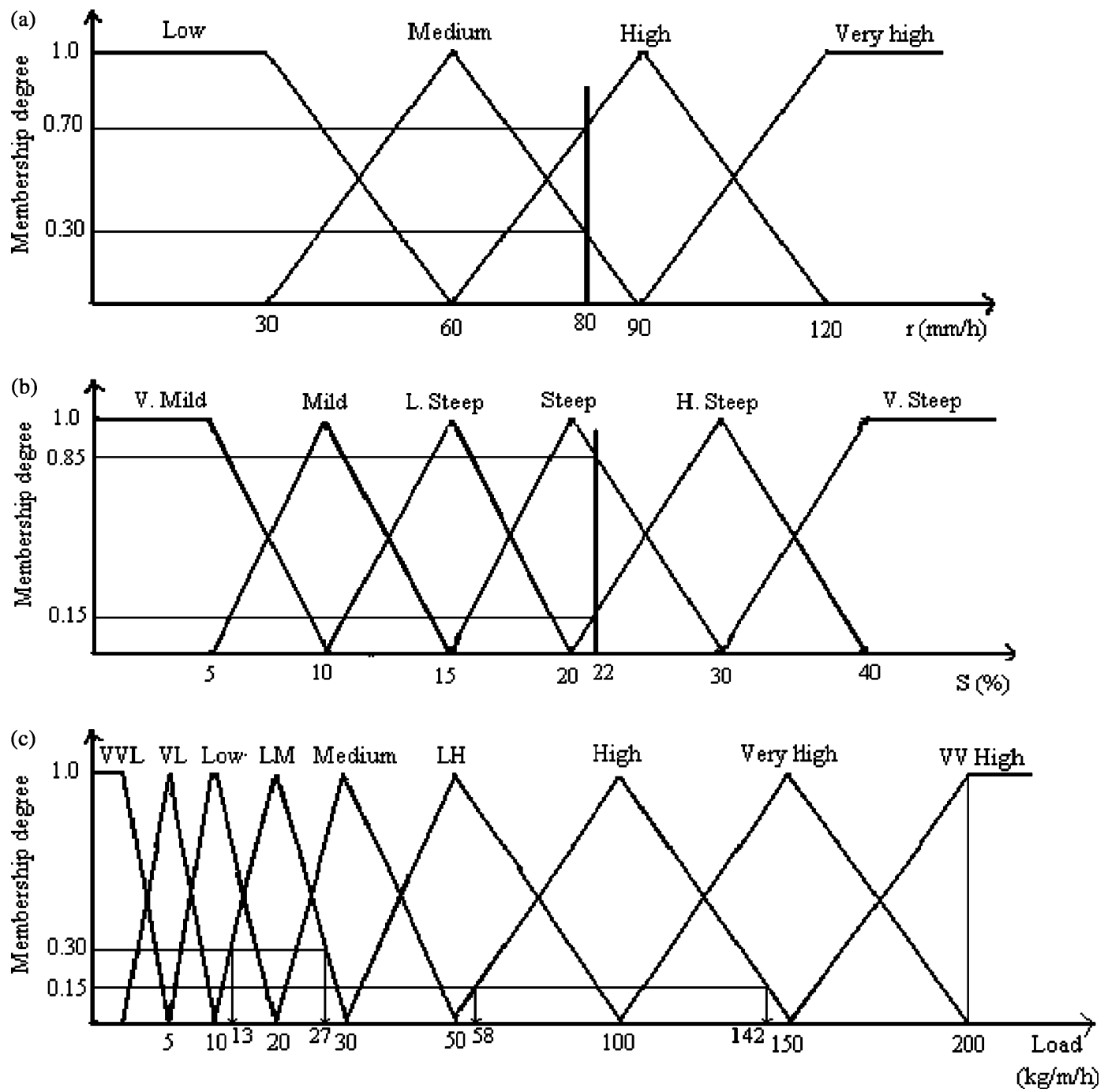

Fig. 2. Fuzzy subsets for (a) rainfall intensity, (b) slope, and (c) sediment load.

Fig. 2b. Finally, sediment discharge is considered to have a maximum of $200 \mathrm{~kg} / \mathrm{m} / \mathrm{h}$ and its subdivision into nine subsets as VVL, VL, L, LM, M, LH, H, VH, and $\mathrm{VVH}$ is considered to have triangular membership functions as represented in Fig. 2c. Subdivisions of the rainfall intensity (Fig. 2a) and slope (Fig. 2b) can be considered valid for most cases encountered in practice. However, the subsets of fuzzy changes in the sediment load domain depend, mainly, on the soil type and surface cover conditions and accordingly the fuzzy partitions can be different for different sites. Note that this study attempts to model the runoff-induced sediment transport from bare soil surfaces by a fuzzy logic algorithm. Hence, the fuzzification of the sediment load in this study (Fig. 2c) is accomplished by considering many experimental data sets of runoff-driven sediment transport from bare soil surfaces.

The sediment load domain is fuzzified in a way to have more subsets. This is because Sen [26] points out that the more subsets there are the greater is the accuracy. Fuzzy rule base contains fuzzy rules that include all possible fuzzy relations between inputs and outputs. These rules are expressed in the IF-THEN format. In the fuzzy approach there are no mathematical equations and model parameters, however, all the uncertainties and model complications are included in the descriptive fuzzy inference procedure in the form of IF-THEN statements.

In this study, fuzzy rules relating the rainfall intensity and slope to sediment discharge were inferred from the experimental data. The antecedent part of the rule (the part starting with IF, up to THEN) included a statement on the rainfall intensity and slope while the consequent part (the part starting with THEN, up to the end) included a statement on sediment discharge. For example 'IF the rainfall intensity is high, and the slope is very steep, THEN the sediment discharge is very high'. Table 1 summarizes the fuzzy rules constructed in this study 
Table 1

Fuzzy rules relating rainfall and slope to sediment load $(\mathrm{L}=$ Low; $\mathrm{M}=$ Medium; $\mathrm{H}=$ High; $\mathrm{V}=$ Very; $\mathrm{Ml}=$ Mild; $\mathrm{S}=$ Steep)

\begin{tabular}{|c|c|c|c|c|}
\hline IF & Rainfall and & Slope & THEN & $\begin{array}{l}\text { Sediment } \\
\text { load }\end{array}$ \\
\hline & $\mathrm{L}$ & VMl & & VVL \\
\hline & $\mathrm{L}$ & Ml & & VVL \\
\hline & $\mathrm{L}$ & LS & & VL \\
\hline & $\mathrm{L}$ & $\mathrm{S}$ & & VL \\
\hline & $\mathrm{L}$ & HS & & VL \\
\hline & $\mathrm{L}$ & VS & & VL \\
\hline & M & VMl & & VVL \\
\hline & M & M & & VL \\
\hline & M & LS & & $\mathrm{L}$ \\
\hline & M & $\mathrm{S}$ & & LM \\
\hline & M & HS & & M \\
\hline & M & VS & & $\mathrm{M}$ \\
\hline & $\mathrm{H}$ & VMl & & VL \\
\hline & $\mathrm{H}$ & M & & $\mathrm{L}$ \\
\hline & $\mathrm{H}$ & LS & & LM \\
\hline & $\mathrm{H}$ & $\mathrm{S}$ & & LH \\
\hline & $\mathrm{H}$ & HS & & $\mathrm{H}$ \\
\hline & $\mathrm{H}$ & VS & & VH \\
\hline & VH & VM1 & & VL \\
\hline & VH & Ml & & LM \\
\hline & VH & LS & & LH \\
\hline & VH & $\mathrm{S}$ & & $\mathrm{H}$ \\
\hline & VH & HS & & VH \\
\hline & VH & VS & & VVH \\
\hline
\end{tabular}

for sediment transport from a bare soil surface. Although these rules, in general, might be considered as valid for the sheet sediment transport mechanism, they may slightly vary depending on the soil type and surface cover conditions.

Fuzzy inference engine takes into account all the possible fuzzy rules in the fuzzy rule base and learns how to transform a set of inputs to corresponding outputs. For example, let us assume that the rainfall intensity is $80 \mathrm{~mm} / \mathrm{h}$ and the slope is $22 \%$, and we want to find out what the fuzzy outputs of sediment discharge under these variables would be. As seen in Fig. 2 a, $80 \mathrm{~mm} / \mathrm{h}$ is a part of 'medium', and 'high' subsets of rainfall intensity with $\mu(r)=0.30$, and $\mu(r)=0.70$ membership degrees, respectively. Similarly, as seen in Fig. 2b, 22\% slope is a part of 'steep', and 'high steep' subsets of slope with membership degrees of $\mu(s)=0.85$, and $\mu(s)=$ 0.15 , respectively. The fuzzy inference engine would consider the following rules from the fuzzy rule base related to the above example and find the degrees of membership of sediment discharge outputs by min operation [27].

IF rainfall intensity is 'high' $(\mu(r)=0.70)$ and slope is 'high steep' $(\mu(s)=0.15)$ THEN sediment discharge is 'high' $(\mu(\mathrm{sed})=\min (0.70,0.15)=0.15)$.

IF rainfall intensity is 'medium' $(\mu(r)=0.30)$ and slope is 'steep' $(\mu(s)=0.85)$ THEN sediment discharge is 'low medium' $(\mu($ sed $)=\min (0.30,0.85)=0.30)$.
Fig. 2c shows the output values of 58 and 142 corresponding to 0.15 degree of membership in the 'high' subset of sediment load and also the output values of 13 and 27 corresponding to 0.30 degree of membership in the 'low medium' subset of sediment load (Fig. 2c).

Defuzzification converts the resulting fuzzy outputs from the fuzzy inference engine to a number. There are several defuzzification methods, such as the weightedaverage, maximum membership, average maximum membership, and center of gravity, etc. In this study, the weighted-average method is employed and it is expressed as [26,27]:

$\operatorname{sed}^{*}=\frac{\sum_{i} \mu\left(\operatorname{sed}_{i}\right) \overline{\operatorname{sed}}_{i}}{\sum_{i} \mu\left(\operatorname{sed}_{i}\right)}$

where $\operatorname{sed}^{*}=$ defuzzified sediment load; $\overline{\operatorname{sed}}_{i}=$ averagesediment load in the $i$ th subset; and $\mu\left(\operatorname{sed}_{i}\right)=$ the membership degree of the sediment load for the $i$ th subset.

When one employs Eq. (1) for the above example, the following output value would be obtained by the weighted-average defuzzification:

$$
\begin{aligned}
\text { sed }^{*} & =\frac{0.15 *(58+142) / 2+0.3 *(13+27) / 2}{(0.15+0.30)} \\
& =46.7 \mathrm{~kg} / \mathrm{m} / \mathrm{h}
\end{aligned}
$$

The details on fuzzy logic are given by Sen $[26,27]$ and Jantzen [11].

\subsection{Artificial neural networks (ANNs)}

In this study, the common three layer-feedforward type of an artificial neural network, as shown in Fig. 3, is constructed. In a feedforward network, the input quantities are fed into input layer neurons, which, in turn, pass them on to the hidden layer neurons after multiplication by a weight. A hidden layer neuron adds up the weighted input received from each input neuron, associates it with a bias, and then passes the result on through a non-linear transfer function. The output neurons do the same operation as that of a hidden neuron. In this study, the sigmoid function, as given in ASCE Task Committee [2], is employed as an activation function.

A back-propagation algorithm accomplishes the learning of ANNs. In the back-propagation algorithm, the optimal weights are found by minimizing a predetermined error function, which has the following form [2]:

$E=\sum_{P} \sum_{p}\left(y_{i}-t_{i}\right)^{2}$

where $y_{i}=$ component of an ANN output vector $\boldsymbol{Y}$; $t_{i}=$ component of a target output vector $\boldsymbol{T} ; p=$ number of output neurons; and $P=$ number of training patterns. The optimal weights would generate an output vector 


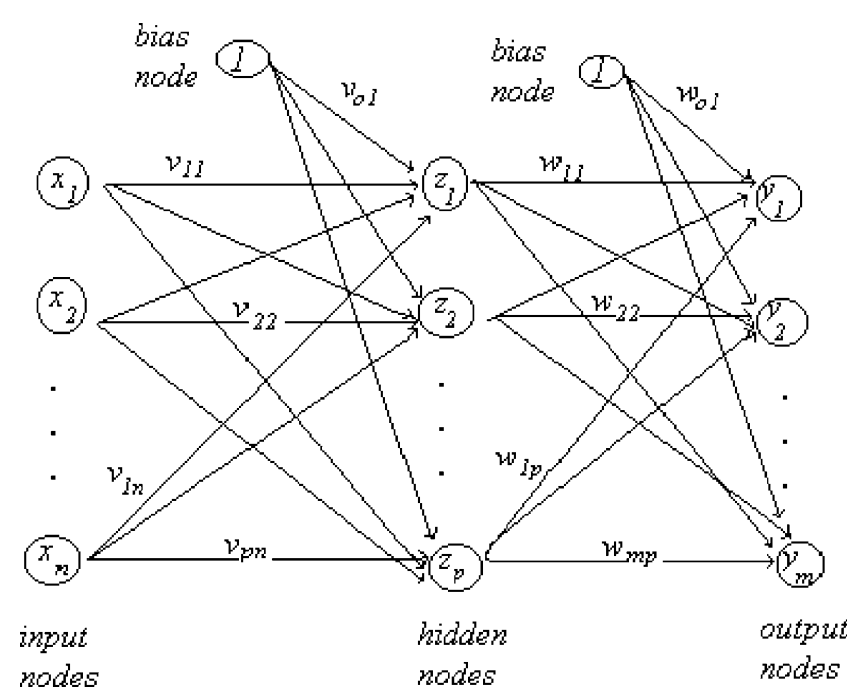

Fig. 3. Schematic representation of feed-forward three layer ANNs.

$\boldsymbol{Y}=\left(y_{1}, y_{2}, \ldots, y_{p}\right)$ as close as possible to target values of the output vector $\boldsymbol{T}=\left(t_{1}, t_{2}, \ldots, t_{p}\right)$ with a selected accuracy.

The-gradient descent method, along with the chain rule of differentiation, is employed to modify the network weights as [2]:

$v_{i j}^{\text {new }}=v_{i j}^{\text {old }}-\delta \frac{\partial E}{\partial v_{i j}}$

where $\delta$ is the learning rate. The network learns by adjusting the biases and weights that link its neurones. However, before the training can begin, the weights and biases of the network must be set to small random values. In this study, random values of 0.2 and -1.0 were assigned to network weights and biases, respectively. Also, due to the nature of the sigmoid function, all external inputs and outputs were converted to the range $(0,1)$ before passing them into a neural network.

The details on ANNs can be obtained from ASCE Task Committee [2] and the details of sediment transport modeling by ANNs can be obtained from Tayfur [34].

\subsection{Physics-based model}

A pair of differential equations mathematically expresses erosion and sediment transport dynamics. These equations, based on the kinematic wave approximation in one dimension, can be expressed as [33]:

$\frac{\partial h}{\partial t}+\frac{\partial}{\partial x}\left(\frac{\sqrt{S}}{n} h^{5 / 3}\right)=(r-i)$

$\frac{\partial(h c)}{\partial t}+\frac{\partial}{\partial x}\left(\frac{\sqrt{S}}{n} h^{5 / 3} c\right)=\frac{1}{\rho_{\mathrm{s}}}\left(D_{\mathrm{rd}}+D_{\mathrm{fd}}\right)$ where

$D_{\mathrm{rd}}=\alpha r^{\beta}\left(1-\frac{z_{\mathrm{w}}}{6.69 r^{0.182}}\right)$

$D_{\mathrm{fd}}=\varphi\left(T_{\mathrm{c}}-\rho_{\mathrm{s}} c \frac{\sqrt{S}}{n} h^{5 / 3}\right)$

where $h=$ the flow depth; $S=$ the bed-slope; $n=$ Manning's roughness coefficient; $r=$ the rainfall intensity; and $i=$ the infiltration rate; $c=$ the sediment concentration by volume; $\rho_{\mathrm{s}}=$ the sediment particle density; $D_{\text {rd }}=$ the soil detachment rate by raindrops; $D_{\mathrm{fd}}=$ the soil detachment/deposition rate by sheet flow; $\alpha$ is the soil detachability coefficient whose range is 0.0006 $0.0086 \mathrm{~kg} / \mathrm{m}^{2} / \mathrm{mm} ; \beta$ is an exponent whose range is 1.0 $2.0 ; z_{\mathrm{w}}$ is the flow depth plus the loose soil depth; and $\varphi$ is the transfer rate coefficient $(1 / \mathrm{L})$ whose range is $3-33$ $\mathrm{m}^{-1}$, and $T_{\mathrm{c}}$ is the flow transport capacity.

The flow transport capacity can be based on one of the dominant variables of shear stress, stream power, unit stream power, and velocity. In two different studies, Tayfur $[33,34]$ investigated the applicability of these approaches to the sheet sediment transport. His results indicate that the velocity approach, in general, performs better than do other models. For that reason, in this study, the fuzzy model will be tested against the physicsbased model whose transport capacity is based on the velocity approach. The velocity approach is expressed as [41]:

$T_{\mathrm{c}}=\eta_{\mathrm{v}}\left(V-V_{\mathrm{c}}\right)^{k_{\mathrm{v}}}$

where $\eta_{\mathrm{v}}=$ the soil erodibility coefficient which takes on values between 0 and $1 ; k_{\mathrm{v}}=$ an exponent whose range is $1.0-2.5 ; V=$ the flow velocity; and $V_{\mathrm{c}}=$ the critical flow velocity defined as a function of particle terminal fall velocity and shear velocity Reynolds number in Yang [41].

Using an implicit centered finite-difference method, Eqs. (5) and (6) were solved numerically. The NewtonRaphson iterative technique was used to solve the set of nonlinear equations resulting from the implicit procedure. The zero-depth and zero-concentration were taken as the upstream boundary conditions while zero-depthgradient and zero-concentration-gradient were taken as the downstream boundary conditions. From the solution of Eq. (5) flow variables were computed. The computed flow variables were, in turn, used in the numerical solution of Eq. (6) where sediment discharges and concentrations were computed. The details are presented by Tayfur [32,33].

\section{Application part}

The developed fuzzy logic algorithm was applied to predict the mean sediment discharge data and compare 
Table 2

Prediction results of the measured mean loads by three models $(\mathrm{g} / \mathrm{m} / \mathrm{s})$

\begin{tabular}{|c|c|c|c|c|c|c|}
\hline & $5.7 \%$ & $10 \%$ & $15 \%$ & $20 \%$ & $30 \%$ & $40 \%$ \\
\hline \multicolumn{7}{|l|}{$32 \mathrm{~mm} / \mathrm{h}$} \\
\hline Observed & 0.10 & 0.29 & 0.56 & 0.63 & 0.93 & 1.35 \\
\hline ANNs & 0.35 & 0.46 & $0.66^{*}$ & $0.96^{*}$ & 2.18 & 5.27 \\
\hline Fuzzy & $0.11^{*}$ & 0.13 & 1.03 & 1.08 & $1.09^{*}$ & $1.35^{*}$ \\
\hline Physics-based & 0.06 & $0.23^{*}$ & 0.82 & 1.56 & 3.19 & 4.89 \\
\hline \multicolumn{7}{|l|}{$57 \mathrm{~mm} / \mathrm{h}$} \\
\hline Observed & 0.30 & 1.50 & 2.81 & 5.71 & 10.17 & 13.08 \\
\hline ANNs & 0.74 & 1.02 & 1.53 & 2.33 & 5.67 & $13.85^{*}$ \\
\hline Fuzzy & $0.26^{*}$ & $1.19^{*}$ & $3.57^{*}$ & $5.95^{*}$ & $11.42^{*}$ & 15.0 \\
\hline Physics-based & 0.50 & 1.97 & 3.89 & $5.89^{*}$ & $9.83^{*}$ & $13.68^{*}$ \\
\hline \multicolumn{7}{|l|}{$93 \mathrm{~mm} / \mathrm{h}$} \\
\hline Observed & 0.65 & 3.68 & 7.11 & 14.95 & 23.10 & 37.96 \\
\hline ANNs & 2.60 & $3.80^{*}$ & 5.96 & 9.37 & $21.80^{*}$ & $41.22^{*}$ \\
\hline Fuzzy & $1.59^{*}$ & 4.68 & $7.81^{*}$ & 19.5 & 33.3 & 45.4 \\
\hline Physics-based & 2.37 & 5.78 & 9.78 & $13.68^{*}$ & $22.07^{*}$ & 28.16 \\
\hline \multicolumn{7}{|l|}{$117 \mathrm{~mm} / \mathrm{h}$} \\
\hline Observed & 1.48 & 5.97 & 12.89 & 26.55 & 37.53 & 65.11 \\
\hline ANNs & 6.57 & 9.68 & $14.98^{*}$ & $22.42^{*}$ & $41.96^{*}$ & $58.85^{*}$ \\
\hline Fuzzy & $2.11^{*}$ & $6.37^{*}$ & 10.61 & $23.60^{*}$ & $42.74^{*}$ & $60.14^{*}$ \\
\hline Physics-based & 3.95 & 8.69 & $14.07^{*}$ & 19.25 & 28.96 & 38.19 \\
\hline
\end{tabular}

${ }^{*}$ Good estimates of the related observed data.

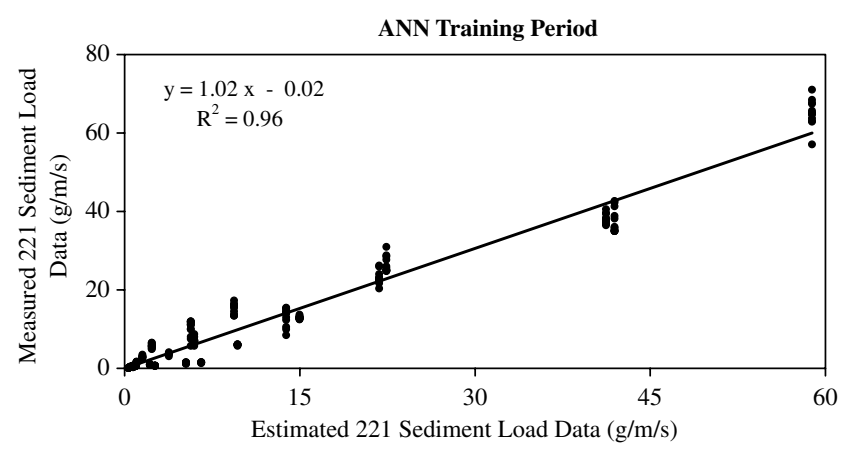

Fig. 4. Performance of ANNs model predicting measured 221 sediment data at the end of training period.

Table 3

Comparison of the three models with respect to different rainfall and slope conditions

\begin{tabular}{clll}
\hline & Mild slope & Steep slope & $\begin{array}{l}\text { Very steep } \\
\text { slope }\end{array}$ \\
\hline Low intensity & $\begin{array}{l}\text { Physics-based } \\
\text { Fuzzy }\end{array}$ & ANN & Fuzzy \\
High intensity & Fuzzy & $\begin{array}{l}\text { Physics-based } \\
\text { Fuzzy }\end{array}$ & $\begin{array}{l}\text { Physics-based } \\
\text { Fuzzy }\end{array}$ \\
$\begin{array}{c}\text { Very high } \\
\text { intensity }\end{array}$ & Fuzzy & $\begin{array}{l}\text { Fuzzy } \\
\text { ANN }\end{array}$ & ANN \\
& & Physics-based & \\
\hline
\end{tabular}

with the measured sediment discharge values. For this purpose, the experimental data from Kilinc and Richardson [12] were used, who performed experimental studies by using a $1.52 \mathrm{~m}$ wide $\times 4.58 \mathrm{~m}$ long flume with an adjustable slope. Six bare slopes of $5.7 \%, 10 \%, 15 \%$, $20 \%, 30 \%$ and $40 \%$ were tested with four different rainfall intensities of $32,57,93$, and $117 \mathrm{~mm} / \mathrm{h}$. On the average, the constant infiltration rate for each run was about $5.3 \mathrm{~mm} / \mathrm{h}$.

Taking experimental data into consideration, rainfall intensity, slope, and sediment load, were fuzzified into fuzzy subsets as shown in Fig. 2a, b, and c, respectively. Rainfall intensity and slope are the input variables while the sediment load is the output variable. The fuzzy rules relating the rainfall intensity and slope to the sediment load were inferred from the experimental data and are summarised in Table 1. The prediction of the mean sediment loads from the 24 runs by the fuzzy model is summarised in Table 2. As seen, the fuzzy model, in general, performs satisfactorily in predicting sediment loads from different slopes under different rainfall intensities. The prediction of the loads, especially, under rainfall intensities of 57 and $117 \mathrm{~mm} / \mathrm{h}$ are quite satisfactory (Table 2).

The fuzzy model was also compared with the physicsbased and ANN models. Before comparison, the calibration of the physics-based model and the training of the ANN model were performed. For the physics-based model calibration, one of the data sets from $20 \%$ slope under $57 \mathrm{~mm} / \mathrm{h}$ rainfall intensity was used. The measured mean sediment load from this experiment is $5.71 \mathrm{~g} / \mathrm{m} / \mathrm{s}$. The calibration run-predicted mean load is $5.89 \mathrm{~g} / \mathrm{m} / \mathrm{s}$. The error is about $3.2 \%$. The calibrated values of the model parameters which resulted in 
this best fit are $n=0.012 ; \alpha=0.0012 ; \quad \beta=1.0$; $\eta_{\mathrm{v}}=0.10 ;$ and $k_{\mathrm{v}}=2.36$. These values are within the ranges suggested in the literature [7]; [28]; [30]. Note that the calibrated physics-based model is applied to predict the mean loads from the other 23 data sets (Table 2).

The ANN model was trained by employing the total number of 221 measured sediment discharge data from the 24 runs. The slope and rainfall intensity data were fed into the system as input while the sediment discharge data were the target output. Fig. 4 shows the observed sediment discharge data versus the sediment data estimated by the ANN model at the end of the training period. As can be seen from Fig. 4, the correlation coefficient $\left(R^{2}\right)$ for this case is about 0.96 and the slope of the related regression equation is almost one and the $y$ intercept of the equation is very close to zero. These results indicate that the training of the ANN model is successfully done. Note that, in the training period, the mean load data from the 24 runs were not used. The trained the ANN model is applied to predict the mean loads of the 24 runs (Table 2).

Table 2 shows the measured mean sediment loads and those predicted by the three models. In order to further summarise the results in Table 2, the following classification is considered:

$\begin{array}{ll}\text { Low rainfall intensity : } & r<40 \mathrm{~mm} / \mathrm{h} \\ \text { High rainfall intensity : } & 40<r<80 \mathrm{~mm} / \mathrm{h} \\ \text { Very high rainfall intensity : } & r>80 \mathrm{~mm} / \mathrm{h} \\ \text { Mild slope : } & S<10 \% \\ \text { Steep slope : } & 10<S<20 \% \\ \text { Very steep slope : } & S>20 \%\end{array}$

Table 3 summarises the results of Table 2 by considering the above classification. Table 3 shows which model performs better depending on the slope and rainfall intensity conditions. The better model is the one which predicts the measured mean load with minimum error. According to Table 3, the fuzzy model, clearly, performs better than do other models in predicting the sediment loads from mild slopes under high and very high rainfall intensities and from very steep slopes under low rainfall intensities. On the other hand, the ANN model performs better than do other models in predicting sediment loads from steep slopes under low rainfall intensities.

\section{Concluding remarks}

In this study, a fuzzy logic algorithm is developed to predict the mean sediment loads from bare soil surfaces subjected to rainfall/runoff-driven sediment transport. The satisfactory prediction of the mean sediment loads by the proposed fuzzy algorithm from the 24 different experimental runs indicate that practitioners for sediment transport studies can reliably employ the fuzzy model. Also, in this study, the fuzzy model is tested against both the ANN and the physics-based models. The models predict the mean sediment loads better, depending on the rainfall and slope conditions, as summarised in Table 3 . Hence, one should take the results in Table 3 into consideration when choosing an appropriate model for predicting the mean sediment loads from bare soil surfaces.

The physics-based model requires data on many model parameters. Further, it involves non-linear partial differential equations whose solution requires complex numerical techniques. In addition, such numerical schemes require iterative methods for the solution of non-linear difference equations and are prone to convergence and instability problems. As such, the simpler fuzzy and ANN models are useful tools today in hydrology especially where the physical parameters are unknown. The ANNs can be synthesised without making use of the detailed and explicit knowledge of the underlying physics and a fuzzy logic algorithm has the ability to describe the knowledge in a descriptive human-like manner in the form of simple rules using linguistic variables.

It should be, however, noted that, as opposed to the physics-based models, the intelligence models of ANN and fuzzy models do not involve by definition any mathematical expressions describing the physics of the process. They are constructed and trained based on available measured data. As such, they perform better in the confines of the training data and poorer anywhere else, where the models are not trained for. This is a major drawback in the case of extrapolating a value of model output from input data that are beyond the range of the training data set. In addition, the intelligence models are not also appropriate for the cases where the space-time distributions of the state variables of interest are required. In engineering problems, however, often such information is required and therefore such drawbacks of the intelligence models are overcome by the physics-based models.

\section{References}

[1] Ahamed TRN, Rao KG, Murthy JSR. Fuzzy class membership approach to soil erosion modeling. Agric Syst 2000;63(2):97110.

[2] ASCE Task Committee. Artificial neural networks in hydrology. I: Preliminary concepts. J. Hydrol. Engng. ASCE 2000;5(2):115123.

[3] Basheer IA, Najjar YM. Designing and analyzing fixed-bed adsorption systems with artificial neural networks. J Environ Syst 1995;23(3):291-312.

[4] Chang NB, Weu GG, Chen YL. A fuzzy multi-objective programming approach for optimal management of the reservoir watershed. Eur J Oper Res 1997;99(2-1):289-302. 
[5] Dou C, Woldt W, Bogardi I, Dahab M. Numerical solute transport simulation using fuzzy set approach. J Contam Hydrol 1997;27(1-2):107-26.

[6] Dou C, Woldt W, Bogardi I. Fuzzy rule-based approach to describe solute transport in the unsaturated zone. J Hydrol 1999;220(1-2):74-85.

[7] Foster GR. Modeling the erosion process. In: Haan CT, Johnson HP, Brakensiek DL, editors. Hydrologic modeling of small watersheds. ASAE; 1982. p. 295-380.

[8] Govindaraju RS, Kavvas ML. Modeling the erosion process over steep slopes: approximate analytical solutions. J Hydrol 1991;127:279-305.

[9] Govindaraju RS, Rao AR. Artificial neural networks in hydrology. Boston: Kluwer Academic Publishers; 2000. 329 pp.

[10] Guldal V, Muftuoglu RF. 2D unit sediment graph theory. J Hydrol Engng, ASCE 2001;6(2):132-40.

[11] Jantzen J. Design of fuzzy controllers, Technical Report, No. 98E864, Department of Automation, Technical University of Denmark, 1999.

[12] Kilinc M, Richardson EV. Mechanics of soil erosion from overland flow generated by simulated rainfall. Hydrology Papers, Colorado State University, Fort Collins, Colorado, Paper 63, 1973.

[13] Leaf C. A model for predicting erosion and sediment yield from secondary forest road construction. Rocky Mountain Forest and Range Exp. Sta., US Dept. Agric., Ft.Collins, CO, Forest Service Res. Note RM-274, 1974.

[14] Lisle IG, Rose CW, Hogarth WL, Hairsine PB, Sander GC, Parlange J-Y. Stochastic sediment transport in soil erosion. J Hydrol 1998;204(1-4):217-30.

[15] Lu R-S, Lo S-L. Diagnosing reservoir water quality using selforganising maps and fuzzy theory. Water Res 2002;36(9):2265-74.

[16] Maier HR, Dandy GC. The use of artificial neural networks for the prediction of water quality parameters. Water Resour Res 1996;32(4):1013-22.

[17] Megahan WF. Erosion over time on several distributed granitic soils: a model. Intermountain Forest and Range Exp. Sta., US Dept. Agric., Ogden, UT, Forest Service Res., Paper INT-156, 1974, 14 pp.

[18] Mitra B, Scott HD, Dixon JC, McKimmay JM. Applications of fuzzy logic to the prediction of soil erosion in large watershed. Geoderma 1998;86(3-4):183-309.

[19] Muttiah RS, Srinivasan R, Allen PM. Prediction of two-year peak stream discharges using neural networks. J Am Water Resour Assoc 1997;33(3):625-30.

[20] Ozelkan EC, Duckstein L. Fuzzy conceptual rainfall-runoff models. J Hydrol 2001;253(1-4):41-68.

[21] Parlange J-Y, Hogarth WL, Rose CW, Sander GC, Hairsine P, Lisle I. Addendum to unsteady soil erosion model. J Hydrol 1999;217(1-2):149-56.

[22] Prasad SN, Singh VP. A hydrodynamic model of sediment transport in rill furrows. IAHS Publication no. 137, 1982, pp. 293-301.

[23] Raj AP, Kumar DN. Ranking multi-criterion river basin planning alternatives using fuzzy members. Fuzzy Sets Syst 1998;100(13):89-99.
[24] Ray C, Klindworth KK. Neural networks for agrochemical vulnerability assessment of rural private wells. J Hydrol Engng, ASCE 2000;5(2):162-71.

[25] Sander GC, Hairsine PB, Rose CW, Cassidy D, Parlange J-Y, Hogarth WL, et al. Unsteady soil erosion model, analytical solutions and comparison with experimental results. J Hydrol 1996;178(1-4):351-67.

[26] Sen Z. Fuzzy algorithm for estimation of solar irradiation from sunshine duration. Sol Energy 1998;63(1):39-49.

[27] Sen Z. Fuzzy modeling in Engineering', Graduate Course Notes, Faculty of Civil Engineering, Istanbul Technical University, Istanbul, Turkey (in Turkish), 1999.

[28] Sharma PP, Gupta SC, Foster GR. Predicting soil detachment by raindrops. Soil Sci Soc Am J 1993;57:674-80.

[29] Singh VP. Analytical solutions of kinematic wave equations fro erosion on a plane: 2. Rainfall of finite duration. Adv Water Resour 1983;6:88-95.

[30] Singh VP. Kinematic wave modeling in water resources: environmental hydrology. New York: John Wiley \& Sons; 1997.

[31] Singh VP, Regl RR. Analytical solutions of kinematic wave equations: 1. Rainfall of infinite durations. Adv Water Resour 1983;6:2-10.

[32] Tayfur G. Modeling two dimensional erosion process over infiltrating surfaces. J Hydrol Engng, ASCE 2001;6(3):259-62.

[33] Tayfur G. Applicability of sediment transport capacity models for non-steady state erosion from steep slopes. J Hydrol Engng, ASCE 2002;7(3):252-9.

[34] Tayfur G. Artificial neural networks for sheet sediment transport. Hydrol Sci J IAHS 2002;47(6).

[35] Tayfur G, Kavvas ML, Govindaraju GS, Storm DE. Applicability of St. Venant equations for two-dimensional overland flows over rough infiltrating surfaces. $\mathrm{J}$ Hydraulic Engng, ASCE 1993;119(1):51-63.

[36] Thirunmalaiah K, Deo MC. Hydrological forecasting using neural networks. J Hydrol Engng, ASCE 2000;5(2):180-9.

[37] Tokar AS, Johnson PA. Rainfall-runoff modeling using artificial neural networks. J Hydrol Engng, ASCE 1999;4(3):232-9.

[38] Tokar AS, Markus M. Precipitation-runoff modeling using artificial neural networks and conceptual models. J Hydrol Engng, ASCE 2000;5(2):156-61.

[39] Tran LT, Ridgley MA, Duckstein L, Sutherland R. Application of a fuzzy logic-based modeling to improve the performance of the revised universal soil loss equation. Catena 2002;47(3):203-26.

[40] Xiong L, Asaad Y, Shamseldin Y, O'Connor KM. A non-linear combination of the forecasts of rainfall-runoff models by the firstorder Takagi-Sugeno fuzzy system. J Hydrol 2001;245(1-4):196217.

[41] Yang CT. Sediment transport theory and practice. McGraw-Hill; 1996.

[42] Yang CC, Prasher SO, Lcroix R, Sreekanth S, Patni NK, Masse L. Artificial neural network model for subsurface-drained farmland. J Irrig Drain Engng ASCE 1997;123(4):285-92.

[43] Yu P-S, Yang T-C. Fuzzy multi-objective function for rainfallrunoff model calibration. J Hydrol 2000;238(1-2):1-14.

[44] Zhu AX, Mackay DS. Effects of spatial detail of soil information on watershed modeling. J Hydrol 2001;248(1-4):54-77. 